\title{
Effectiveness of the Mediterranean diet in the elderly
}

\author{
Blanca Roman' \\ Laura Carta ${ }^{2}$ \\ Miguel Ángel \\ Martínez-González ${ }^{3}$ \\ Lluís Serra-Majem ${ }^{4}$
}

'Mediterranean Diet Foundation, University of Barcelona Science Park, Spain; ${ }^{2}$ Department of Biosystems and Applied Sciences, Unit of Physiology and Human Nutrition, University of Cagliari, Italy; ${ }^{3}$ Department of Epidemiology and Public Health, University of Navarra, Spain; ${ }^{4}$ Department of Clinical Sciences, University of Las Palmas de Gran Canaria, Spain
Correspondence: Lluís Serra Majem Mediterranean Diet Foundation, Parc Cientific de Barcelona, Baldiri Reixac, 4 Torre D, 08028 Barcelona, Spain

Tel +3493403454l

Fax +34934034543

Email Iserra@dcc.ulpgc.es

\begin{abstract}
The Mediterranean diet is known to be one of the healthiest dietary patterns in the world due to its relation with a low morbidity and mortality for some chronic diseases. The purpose of this study was to review literature regarding the relationship between Mediterranean diet and healthy aging. A MEDLINE search was conducted looking for literature regarding the relationship between Mediterranean diet and cardiovascular disease (or risk factors for cardiovascular disease), cancer, mental health and longevity and quality of life in the elderly population (65 years or older). A selection of 36 articles met the criteria of selection. Twenty of the studies were about Mediterranean diets and cardiovascular disease, 2 about Mediterranean diets and cancer, 3 about Mediterranean diets and mental health and 11 about longevity (overall survival) or mental health. The results showed that Mediterranean diets had benefits on risks factors for cardiovascular disease such as lipoprotein levels, endothelium vasodilatation, insulin resistance, the prevalence of the metabolic syndrome, antioxidant capacity, the incidence of acute myocardial infarction, and cardiovascular mortality. Some positive associations with quality of life and inverse associations with the risk of certain cancers and with overall mortality were also reported.
\end{abstract}

Keywords: Mediterranean diet, elderly, health, review

\section{Introduction}

According to the 2002 World Health Organization (WHO) health report, a diet poor in fruits and vegetable is the third preventable risk factor for chronic diseases (specific types of cancers, cerebrovascular diseases and ischemia) which have replaced infectious disease as the leading cause of morbidity and mortality in the world. The same report showed that among the twenty countries with the highest life expectancy in the world, four of them are Mediterranean countries (France, Italy, Spain, and Greece) (WHO 2001).

Mediterranean countries share a common dietary pattern first defined by Ancel Keys (Keys et al 1986) when he observed important geographical differences in the incidence rates of cardiovascular disease, certain cancers and other nutrition-related diseases that were mostly attributable to supposedly unhealthy food patterns whereas the Mediterranean dietary pattern was considered as the responsible factor for health advantages. Such pattern was the main focus of study in 1993 at the International Conference on the Diets of the Mediterranean, although the Mediterranean dietary pattern had been previously defined in other meetings (Helsing et al 1989; Serra Majem et al 1993; Nestle et al 1995; Willett et al 1995). Mediterranean dietary patterns are comprised of: abundant plant foods (fruits, vegetables, breads, other forms of cereals, pulses, nuts and seeds); minimally processed, seasonally fresh and locally grown foods; fresh fruits as the typical daily dessert with sweets elaborated from nuts, olive oil and concentrated sugars or honey that are consumed during feast days; olive oil as the principal source of dietary lipids; dairy products (mainly cheese and yoghurt) consumed in low to moderate amounts; fewer than four eggs consumed per week; 
red meat consumed in low frequency and amounts; wine consumed in low to moderate amounts, and generally taken with meals. Such a dietary pattern assures a sufficient intake of certain nutrients that have been related in some way with a reduced risk of several chronic diseases. Various scores or indexes have been developed to assess the adherence to the Mediterranean diet pattern in the population and to link such patterns with several nutrient-related diseases (Bach et al 2006).

There is increasing available evidence that following a Mediterranean style diet correlates to higher longevity and delays the onset of the deterioration in health, not only in countries from the Mediterranean Basin but in other nonMediterranean countries as well (Kouris-Blazos et al 1999; Havenam-Nies et al 2003). However, what ageing people aspire for is not only longer life but also optimal quality of life free of disability or disease that implies being dependent on others. As higher self-rating of health is associated to reduced mortality not only among elderly people but among the general population as well (Idler and Benyamini 1997), identifying which factors contribute to manage healthy aging is key for increasing the percentage of the population who enjoys their longevity. In this context, the relevant question should be: does the Mediterranean diet have any relationship to better self-rated health?

The purpose of this article is to review literature regarding the Mediterranean diet and its effects on healthy aging.

\section{Material and methods}

A search of the MEDLINE databases was performed. The keyword "Mediterranean diet" or related term (Mediterranean diet score, Mediterranean dietary pattern) were included as a criterion search. As a second search the following words were included: "cardiovascular disease", "coronary syndrome", "dislipaemia", "blood cholesterol”, "hypertension", "diabetes", "obesity", "overweight”, "waist circumference”, "metabolic syndrome", "inflammatory markers", "endothelial function", “cancer", "neurodegenerative diseases", "dementia", “depression", “Alzheimer disease", "mental health", "health", "longevity", "quality of life".

Only those studies which evaluate the Mediterranean diet as a dietary pattern where taken into account, excluding those which evaluated single food items or nutrients, although they pertain to the Mediterranean dietary pattern. Only studies which included individuals of 65 years or older at the starting point of the study were analyzed. We excluded studies that evaluated the effect of a single Mediterranean Diet meal on the subjects under study and studies conducted in animals. Additional publications were identified from references published in the original papers.

\section{Results}

A total of 39 publications were selected, three of them were rejected because they did not accomplish the criterion of inclusion regarding the disorders they investigated. All results are summarized in Table 1. Publications were classified into four groups according to the main outcome they assessed: cardiovascular disease (including risk factors such as high blood pressure, hypercholesterolemia, diabetes, obesity, the metabolic syndrome and inflammatory markers of cardiovascular damage), cancer, mental health (including dementia, Alzheimer's disease and depression) and longevity and quality of life.

Twenty-one of the studies were about Mediterranean diets and cardiovascular disease, 8 of them being clinical trials. Two of the publications were about Mediterranean diets and cancer, three about Mediterranean diets and mental health and 11 about longevity or mental health. Twenty-two of the publications showed results from Mediterranean countries (Italy, Spain, France, and Greece), 10 from non Mediterranean countries (United Kingdom, Canada, Australia, USA, Denmark, Germany, and The Netherlands) and 4 from multicenter studies in Europe and the United States.

An overwhelming majority of them were beneficial, with very little evidence of null findings and no evidence of harm in any study (Table 1).

\section{Discussion}

Since the Seven Countries study publication, an increasing number of studies have supported the beneficial role of the Mediterranean diet on health prevention. There is a rapidly growing recent trend of good-quality observational studies and trials assessing the cardioproctetive role of Mediterranean diets (Martínez-González et al 2004). The present review focused on existing evidence for the role of the Mediterranean dietary pattern on aging, or better stated, on successful aging. Modern medicine has managed to add years to life but not to delay the onset of chronic diseases, which implies a greater prevalence of disabilities and dependent people who suffer from any one of the most prevalent chronic diseases. In fact, much of the health-care costs associated to aging are attributed not to chronic disease per se but to activity limitations and all that this represents (Chan et al 2002). The research was restricted to the most prevalent non-communicable diseases leading to disability in older individuals from developed 


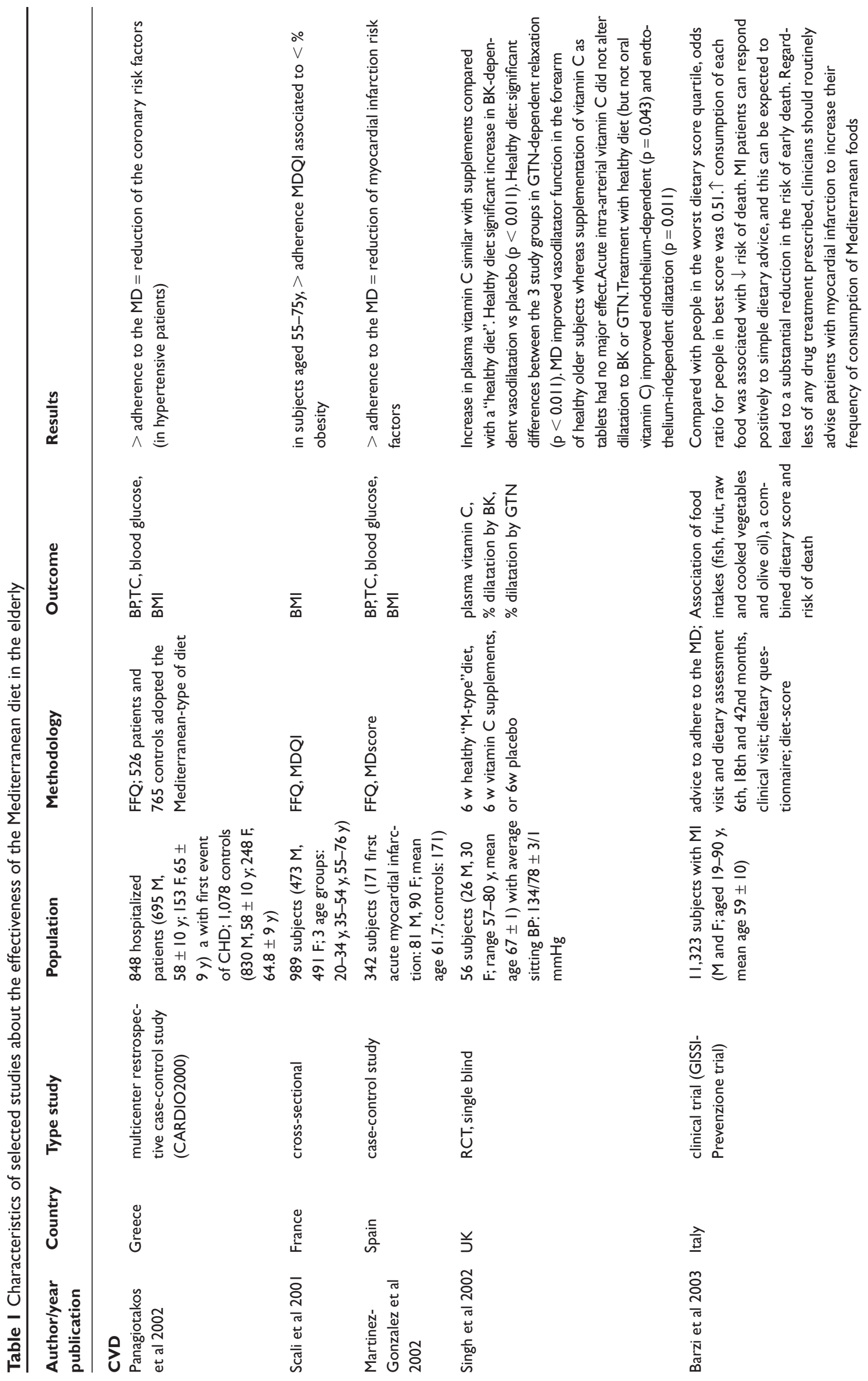




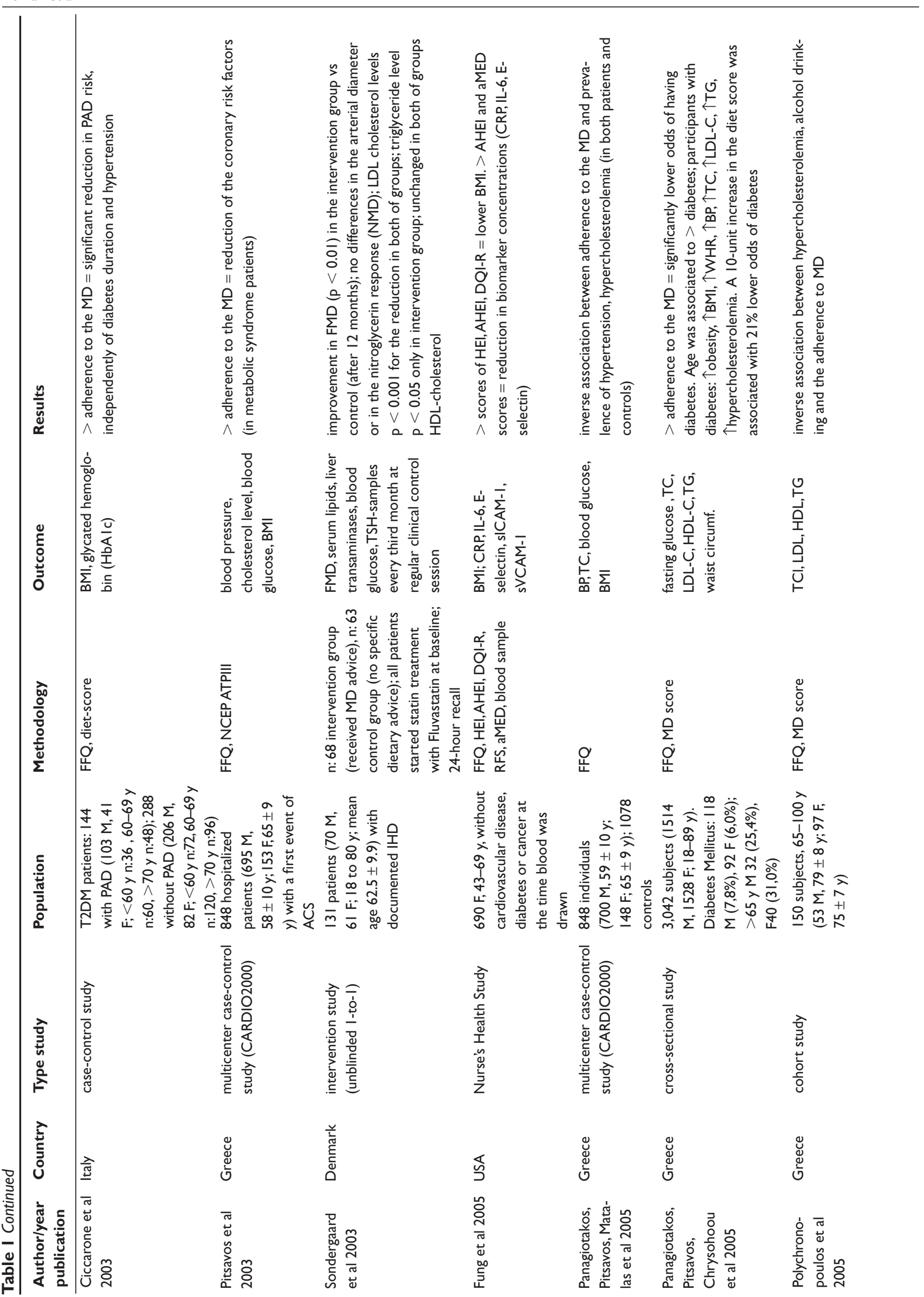




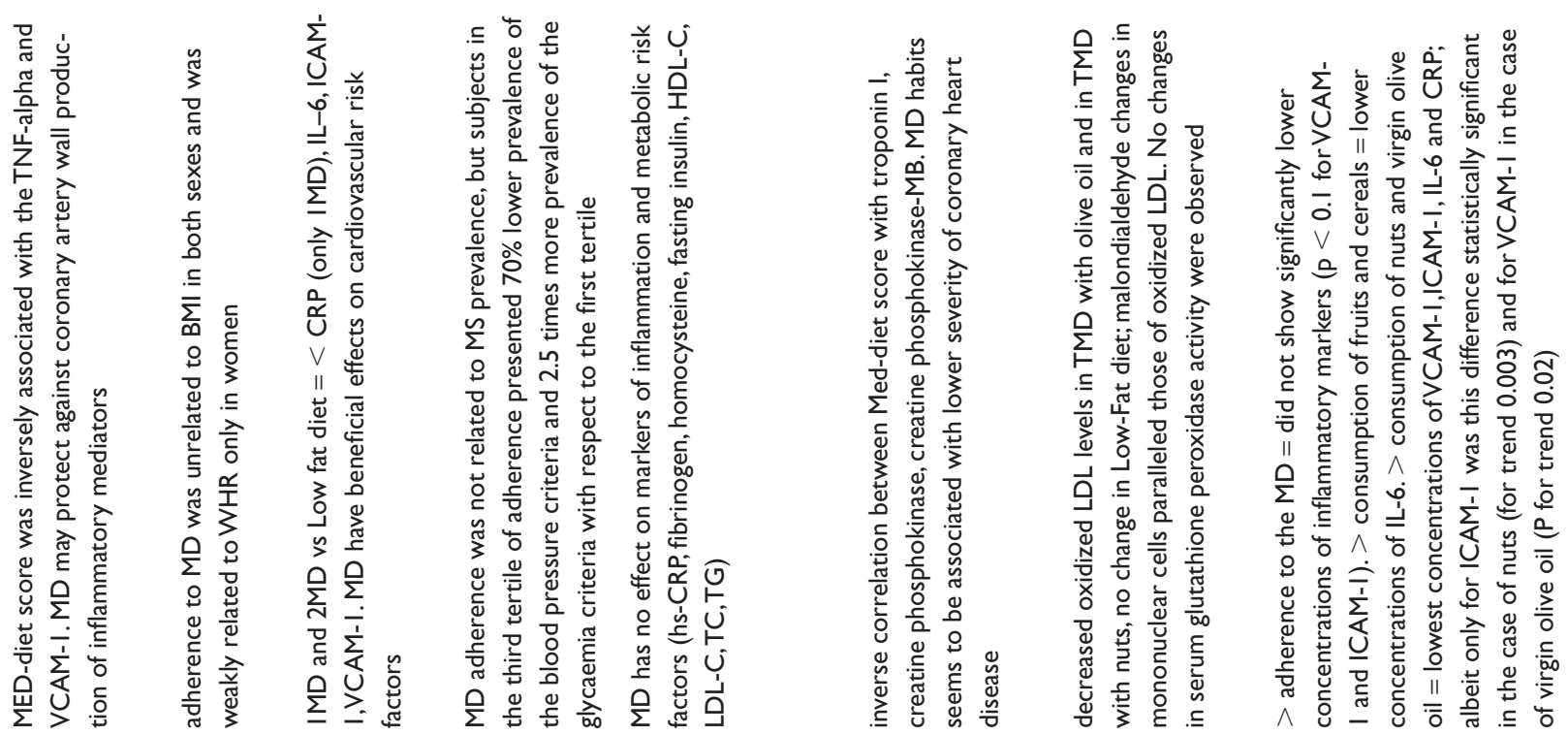

\section{I}

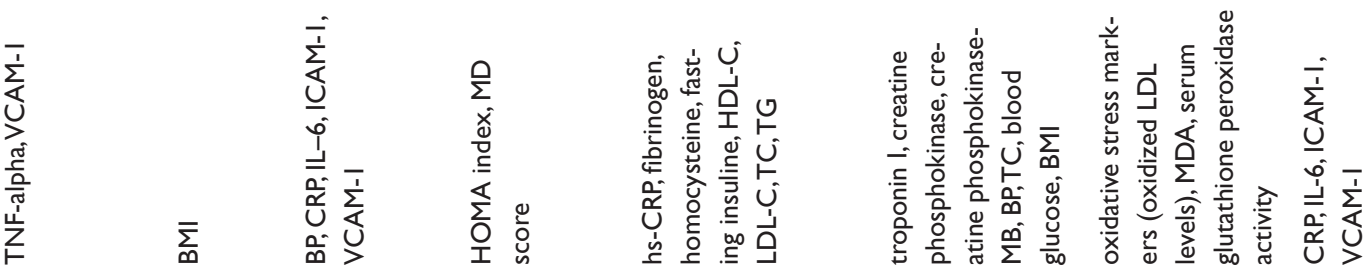

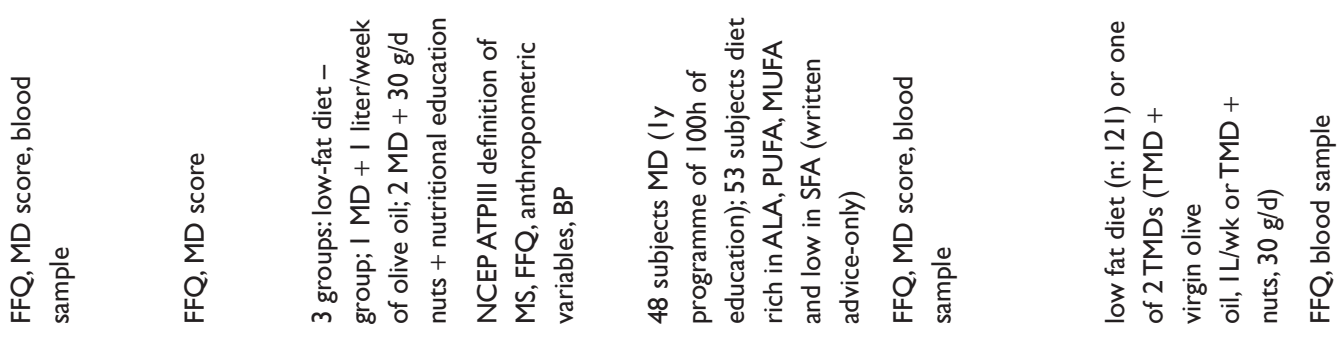

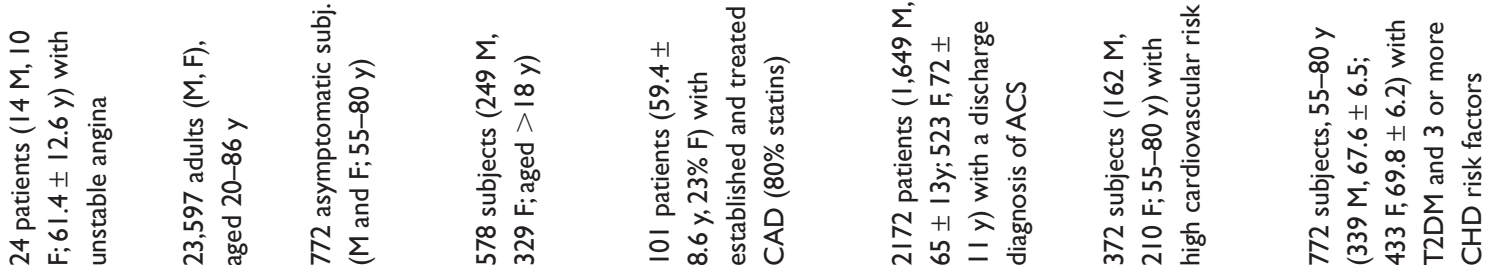

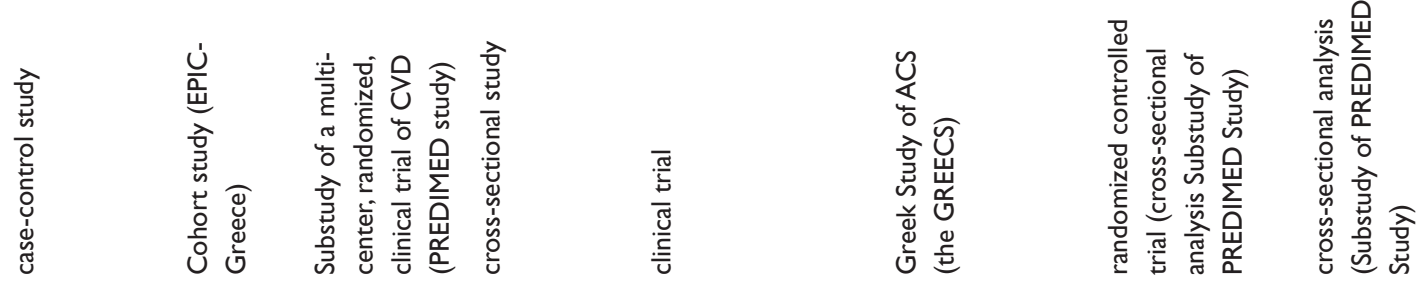

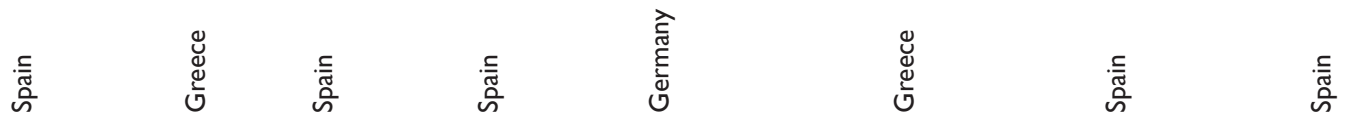

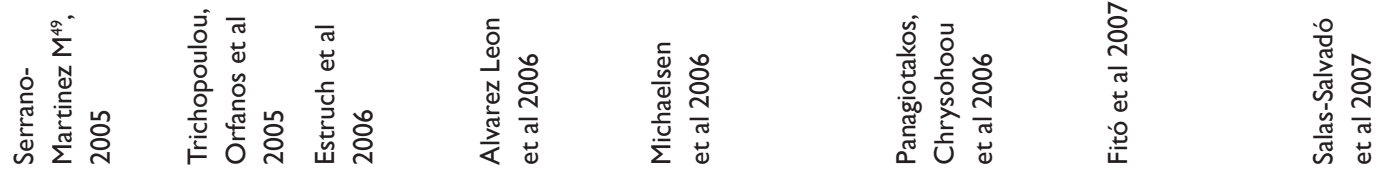




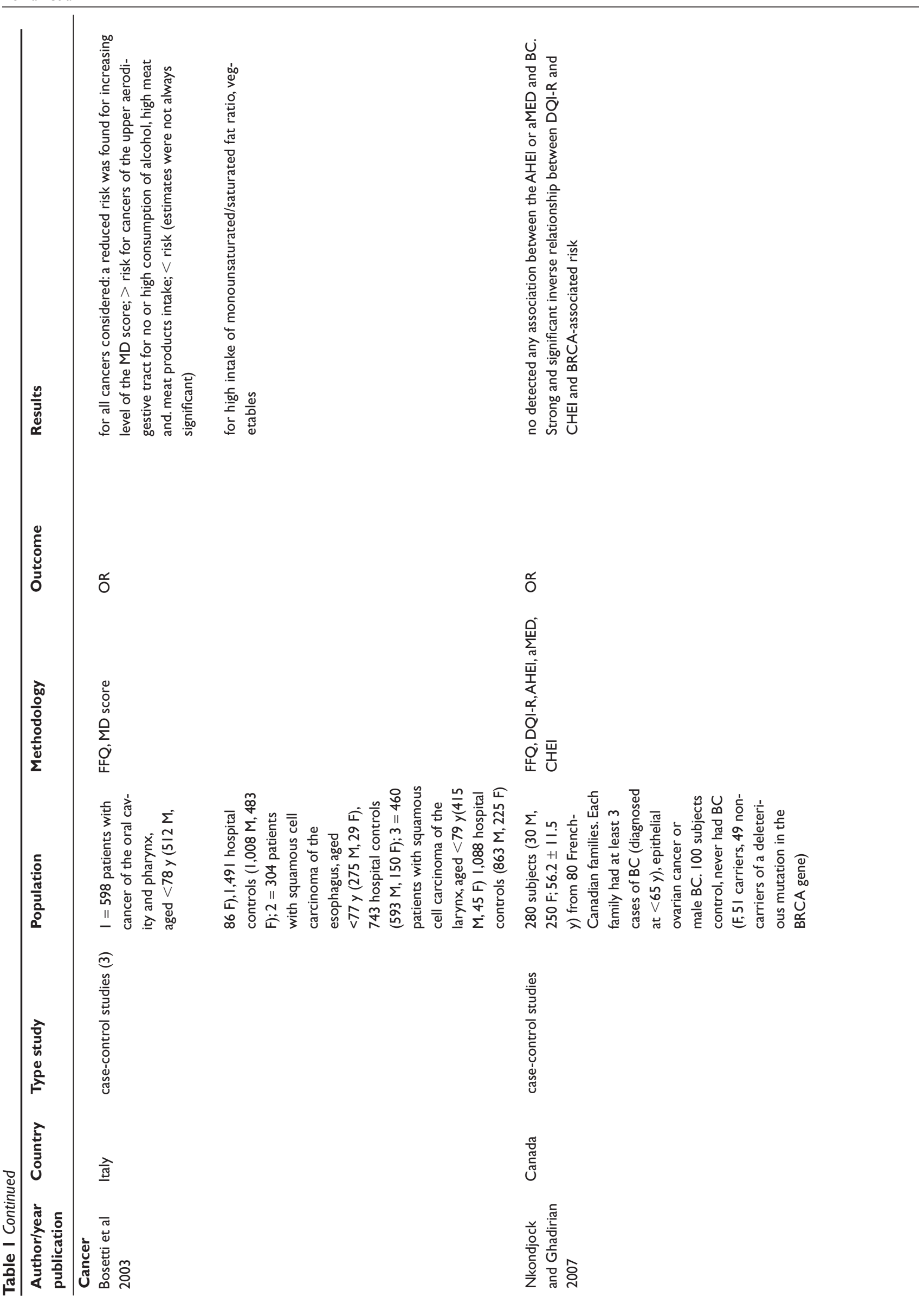



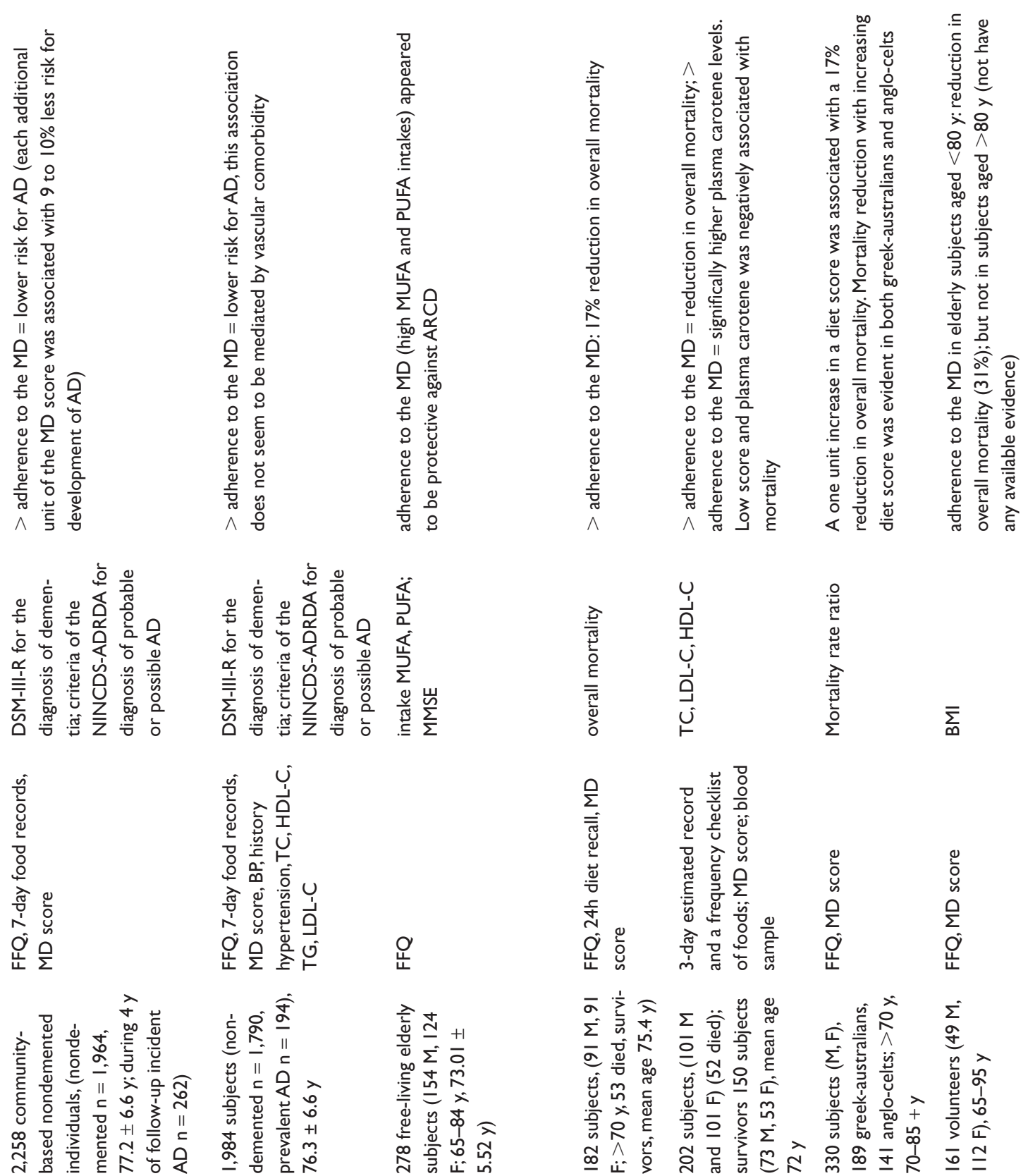

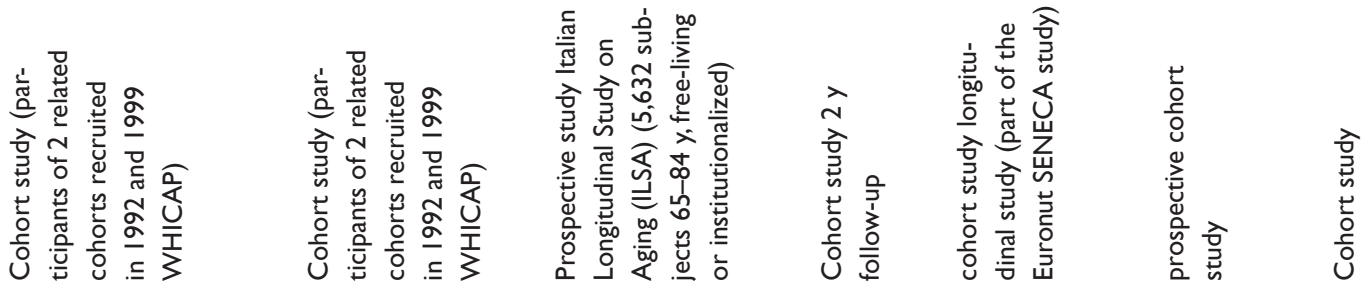

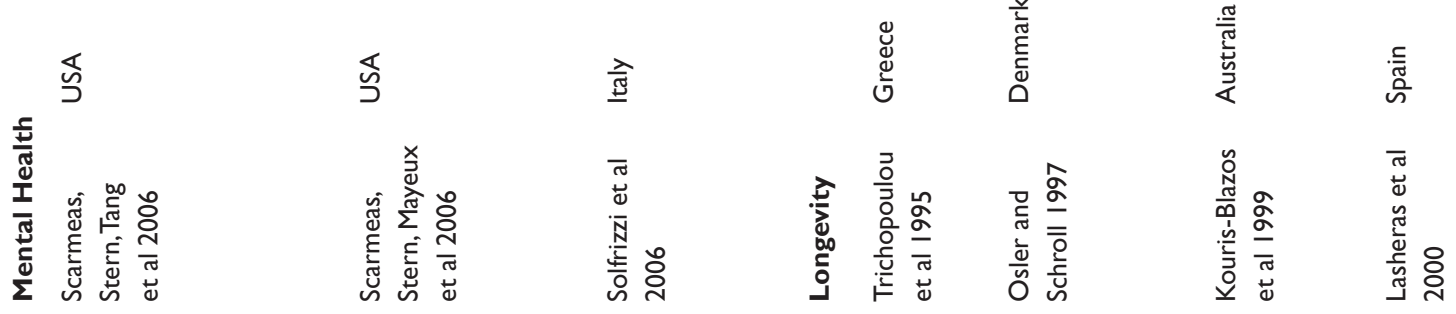







countries (cardiovascular diseases, certain types of cancer and neurodegenerative diseases) (Lopez et al 2006).

Referring to cardiovascular diseases, the review showed that the Mediterranean diet might exert some effect not only through its impact on the principal risk factors for such diseases but also on the severity of the disease once it appears. Several observational studies (Psaltopoulou et al 2004; Polychronopoulos et al 2005; Panagiotakos, Pitsavos, Chrysohoou, et al 2005; Panagiotakos, Pitsavos, Matalas, et al 2005; Fung et al 2005; Serrano Martinez et al 2005; Panagiotakos et al 2006 ) and intervention studies (Singh et al 2002; Sondergaard et al 2003; Fitó et al 2007; Salas-Salvadó et al 2007) have associated the Mediterranean diet pattern to lower levels of blood pressure, blood cholesterol, diabetes, inflammation and improved coagulation process and endothelial function, even in individuals with diabetes (Ciccarone et al 2003) or the metabolic syndrome (Pitsavos et al 2003; Álvarez León et al 2006). Recently, a cross sectional study conducted in Cyprus reported that individuals from 65 to 100 years with a higher adherence to the Mediterranean diet showed lower levels of blood cholesterol even among those treated with statins (Polychronopoulos et al 2005). Moreover, certain observational studies showed that the severity of acute coronary syndrome in hospital death and rehospitalization (the GREECS study, in males aged 65 and women aged 72 years) and the likelihood of having acute coronary syndromes (the CARDIO2000 study, in individuals from $61 \pm 10$ years) were lower among individuals following a Mediterranean style diet (Martínez-González et al 2002; Panagiotakos et al 2005; Panagiotakos et al 2006). These results were in accordance with the findings reported by Lorgeril in the Lyon Heart study or by Barzi in the GISSI Prevezione trial (de Lorgeril et al 1999; Barzi et al 2003). The PREDIMED study, a primary prevention trial conducted in samples of elderly individuals showed that after three months of following a Mediterranean Diet, individuals improved their lipid profile and reduced blood concentrations of inflammatory molecules (Estruch et al 2006; Fitó et al 2007).

With respect to obesity, although some observational and prospective studies in younger individuals (Schroder et al 2004; Mendez et al 2006; Panagiotakos et al 2006) reported an inverse relationship with adherence to the Mediterranean diet and BMI and obesity, Trichopoulou's data of older individuals from the EPIC study (Trichopoulou et al 2005b) and the SUN prospective cohort (SanchezVillegas et al 2006) found lower BMI among subjects more adherent to the Mediterranean diet but they did not show any independent significant relationship. In a study comparing 
individuals from the Framingham and the SENECA study, a lower waist circumference and BMI were reported in individuals representing high dietary quality not only for the Mediterranean diet but also for scores evaluating other types of dietary patterns (Havenam-Nies et al 2001). A cross sectional study conducted in France with a small sample showed that, especially among older individuals, a poor qualification of the Mediterranean Diet Quality index was associated to a higher prevalence of obesity (Scali et al 2001). These results were corroborated in the PREDIMED study, which demonstrated that the intervention did not imply an increase in body weight of participants (Estruch et al 2006). Recent clinical trials have reported benefits of the Mediterranean diet for several aspects of factors related to the incidence or prognosis of cardiovascular disease in individuals with given risk factors such as the diabetic population (Rodriguez Villar et al 2004; Antonopoulou et al 2006), even when relatively high dietary fat content and unrestricted salt intake were permitted.

The metabolic syndrome, a constellation of risk factors for cardiovascular disease, has also been related to the Mediterranean diet, but not without a certain degree of controversy. Data from a cross sectional study in the Canary Islands in Spain revealed that higher adherence to the Mediterranean diet was not related to a lower prevalence of metabolic syndrome (Álvarez et al 2006). Another cross-sectional study with data from five Mediterranean countries showed no relationship between the Mediterranean diet and the prevalence of the metabolic syndrome (Thanopoulou et al 2006), although a randomized clinical trial from Esposito (Esposito et al 2004) showed that after two years of intervention following a Mediterranean diet, a sample of middle age individuals had reduced the prevalence of metabolic syndrome, inflammatory markers and insulin resistance had declined and endothelial function had improved. On the contrary, another intervention study conducted in Germany showed no impact of adoption of the Mediterranean diet on inflammatory and metabolic risk markers in a sample of patients with coronary artery disease (Michaelsen et al 2006), results that some authors attribute to the study design or the effect the Mediterranean diet had on plasma fatty acid concentrations (Serrano-Martínez and Martínez-González 2007). Moreover, the PREDIMED study did not show a statistically significant relationship between a higher Mediterranean diet score and lower inflammatory biomarkers in the baseline cross-sectional assessment (Salas et al 2007). However, these markers of inflammation significantly improved with the Mediterranean diets after three months of intervention (Estruch et al 2006). There are no cohort studies of Mediterranean diets assessing the incidence of the metabolic syndrome as the outcome.

Adiponectin, a beneficial adipose tissue-secreted cytokine, has been shown to improve insulin sensitivity, to regulate glucose and lipid metabolism, and to have pronounced antiatherosclerotic effects. The levels of circulating plasma adiponectin have been reported to be positively associated with the adherence to a Mediterranean-type dietary pattern among diabetic women (Mantzoros et al 2006).

The role that the Mediterranean diets may have on cancer prevalence has been studied for breast cancer and upper aerodigestive tract cancer. In a cohort of Canadian individuals with a family history of breast cancer or ovarian cancer, no significant association was found between adherence to a Mediterranean diet pattern and risk of BRCA mutationrelated breast cancer (Nkondjock and Ghadirian 2007). As the authors stated, alcohol consumption linked to the Mediterranean dietary pattern may have had some effect on such results. On the contrary, data from three case-control studies in Italy showed a reduced risk of cancer of the oral cavity and pharynx, esophagus, and larynx for increasing levels of the Mediterranean diet score (Bosetti et al 2003). In addition, a four year follow-up of the Lyon Heart study showed a protective effect of the Mediterranean diet for certain cancers (de Lorgeril 1998).

Greater adherence to Mediterranean Diet has been related to improved mental depression, age related cognitive decline and Alzheimer's disease. Age related cognitive decline has recently been defined as an objective decline in cognitive functioning associated to aging but within the normal limits according to the person's age. Although defined as a normal process, its progression may be prevented. The Mediterranean dietary pattern may exert its effects on mental health through different mechanisms: ensuring an adequate intake of B vitamins, folate, and $\omega$-3 fatty acids, which are all involved in the synthesis of certain central nervous system neurotransmitters and phospholipids. In addition, other favorable factors include its effect on vascular mechanisms (lowering certain risk factors such as hypertension, dyslipemia and diabetes or assuring lower homocysteine levels) through its antioxidant properties.

The relationship between Alzheimer's disease and nutrients are being widely explored (Solfrizzi et al 2003; Luchsinger and Mayeaux 2004) but little data on the relationship with the Mediterranean diet is available. Data from the Washington Heights-Inwood Columbia Aging Project in a non 
Mediterranean population showed that higher adherence to the Mediterranean diet was associated with a reduction in the risk for Alzheimer's disease and a slower cognitive decline, in a dose-response manner, taking into account other confounding factors for Alzheimer's disease (Scarmeas, Stern, Mayeux, et al 2006; Scarmeas, Stern, Tang, et al 2006). After almost nine years of follow up, the Italian Longitudinal Study on Aging showed that a diet high in monounsaturated and polyunsaturated fatty acids was associated with better cognitive performance in elderly individuals following a typical Mediterranean diet (Solfrizzi et al 2006).

Depression is known to be the leading cause of years of life lived with disability especially among females (López et al 2006). Few studies have related such disorders with Mediterranean diet adherence. The SUN (Seguimiento Universidad de Navarra) study, a prospective cohort study that analyzed the relationship between dietary intake and some chronic diseases reported an inverse association between vitamin $B_{12}$ and $\omega$-3 fatty acids intake and depression among women, and folate intake and depression among men (Sanchez Villegas 2006).

Studies developed in Mediterranean countries (Trichopoulou et al 1995; Lasheras et al 2000; Trichopoulou et al 2003) and non-Mediterranean countries (Osler and Schroll 1997, Kouris-Blazos et al 1999) have shown a decrease in overall mortality in relation to a high score evaluated by various types of Mediterranean diet indexes. Some of the studies had small samples (Trichopoulou et al 1995; Osler and Schroll 1997, Kouris-Blazos et al 1999; Lasheras et al 2000), whereas others had large samples of the population (Trichopoulou et al 2003). The studies showed that a one point increment in the diet score was associated with a percent reduction in total mortality that ranged from $17 \%$ (Trichopoulou et al 1995, Kouris Blazos et al 1999) to 31\% (Lasheras et al 2000) and that a two point increase in such a score reduced overall mortality by $25 \%$ (Trichopoulou et al 2003). Although the protective effect has been shown to be stronger for individuals older than 55 years, some authors reported benefits in young women as well (Lagiou et al 2006). Data from the SENECA and FINE studies conducted in Europe also showed that a Mediterranean diet score of 4 or more was associated with a lower risk of all-cause mortality (Havenam-Nies et al 2003; Knoops et al 2004). Moreover, a modified Mediterranean diet score developed to take into account the different patterns in the use of added lipid in northern European countries showed that a two unit increment corresponded to an $8 \%$ reduction in overall mortality (Trichopoulou et al 2005). When evaluating the role the
Mediterranean diet had on overall mortality in individuals suffering from a previous myocardial infarct, a higher adherence to Mediterranean diet was also associated to lower overall mortality (Trichopoulou et al 2005; Iestra et al 2006). In a recent nationwide study on Greek centenarians, the participants reported following a typical Mediterranean diet (Stathakos et al 2005). On the other hand studies conducted in non Mediterranean countries reported that their own healthy traditional diet was more accurate to predict longevity than a Mediterranean style diet (Waijers et al 2006).

The results found in this review support the role investigators have attributed to the Mediterranean diet. Unfortunately, although the number of publications about the Mediterranean diet and its health benefits is increasing (Serra-Majem et al 2006), the adherence to such dietary pattern is declining, even in the heart of the area where the Seven Countries study was conducted (Kafatos et al 1997). As Barzi et al (2003) remarks, when simple dietary advice adopted as therapeutic clinical intervention yields the type of results seen in the GIZZI study, such advice should be translated into dietary guidelines and should be addressed not only to coronary patients but to the entire population, especially when such an intervention is as cost-effective as demonstrated (Dalziel et al 2006). Otherwise, such efforts are naught as there will be no application of the findings in terms of what component/s of the Mediterranean diet is/are responsible for the health effects of such a dietary pattern.

\section{Acknowledgments}

The authors thank Joy Ngo for supervision of the English writing.

Grant Support: By the Spanish Ministry of Health (RED: Alimentación saludable en la prevención primaria de enfermedades crónicas: la Red Predimed. Dentro de las Redes Temáticas de Investigación Cooperativa Sanitaria (RETICs). Fondo de Investigación Sanitaria, RD06/0045/0009).

\section{References}

Alvarez Leon EE, Henriquez P, Serra Majem L1. 2006. Mediterranean diet and metabolic syndrome: a cross-sectional study in the Canary Islands. Public Health Nutr, 9:1089-98.

Antonopoulo S, Fragopoulou T, Karantonis HC, et al. 2006. Effect of traditional Greek Mediterranean meals on platelet aggregation in normal subjects and in patients with type 2 diabetes mellitus. T Medical Food, 9:356-62.

Bach A, Serra-Majem L, Carrasco JL, et al. 2006. The use of indexes evaluating the adherence to the Mediterranean diet in epidemiological studies: a review. Public Health Nutr, 9:132-46.

Barzi F, Woodward M, Marfisi RM, et al. 2003. Mediterranean diet and all-causes mortality after myocardial infarction: results from the GISSIPrevenzione trial. Eur J Clin Nutr, 57:604-11.

Bosetti C, Gallus S, Trichopoulou A, et al. 2003. Influence of The Mediterranean Diet on the risk of the cancers upper aerodigestive tract. Cancer Epidemiol, Biomarkers Prev, 12:1091-4. 
Chan L, Beaver S, MacLeosse R, et al. 2002. Dissability and health care costs in the Medicare population. Arch Phys Med Rehabil, 83:1196-201.

Ciccarone E, Di Castelnuovo A, Salcuni M, et al. 2003. A high-score Mediterranean dietary pattern is associated with a reduced risk of peripheral arterial disease in Italian patients with Type 2 diabetes. $J$ Thromb Haemost, 1:1744-52.

Dalziel K, Segal L, de Lorgeril M. 2006. A Mediterranean diet is costeffective in patients with previous myocardial infarction. $J$ Nutr, 136:1879-85.

de Lorgeril M, Salen P, Martin JL, et al. 1998. Mediterranean dietary pattern in a randomized trial: prolonged survival and possible reduced cancer rate. Arch Intern Med, 158:1181-7.

de Lorgeril M, Salen P, Martin JL, et al. 1998. Mediterranean diet, traditional risk factors, and the rate of cardiovascular complications after myocardial infarction: final report of the Lyon Diet Heart Study. Circulation, 99:779-85.

Esposito K, Marfella R, Ciotola M, et al. 2004. Effect of a Mediterranean-style diet on endothelial dysfunction and markers of vascular inflammation in the metabolic syndrome: a randomized trial. JAMA, 292:1440-6.

Estruch R, Martinez-Gonzalez MA, Corella D, et al. 2006. Effects of a Mediterranean-Style diet on Cardiovascular risk factors. Ann Intern Med, 145:1-11.

Fitó M, Guxens M, Corella D, et al. 2007. Effect of a traditional Mediterranean Diet on lipoprotein oxidation: a randomized controlled trial. Arch Intern Med, 167:1195-203.

Fung TT, McCullough ML, Newby PK, et al. 2005. Diet-quality scores and plasma concentrations of markers of inflammation and endothelial dysfunction. Am J Clin Nutr, 82:163-73.

Haveman-Nies A, Tucker KL, de Groot LCPGM, et al. 2001. Evaluation of dietary quality in relationship to nutritional and lifestyle factors in elderly people of the US Framingham Heart Study and the European SENECA study. Eur J Clin Nutr, 55:870-80.

Haveman-Nies A, de Groot LCPGM, van Staveren WA. 2003. Dietary quality, lifestyle factors and healthy ageing in Europe: the SENECA study. Age and Aging, 32:427-34.

Helsing E, Trichopoulou A, eds. 1989. The Mediterranean diet and food culture - a symposium. Eur J Clin Nutr, 43(Suppl 1):1-92.

Idler EL, Benyamini Y. 1997. Self-rated health and mortality: a review of twenty-seven community studies. J Health Soc Behav, 38:21-37.

Iestra J, Knoops K, Kramhart D, et al. 2006. Lifestyle, Mediterranean diet and survival in European post myocardial infarction patients. Eur $J$ Cardiovasc Prev Rehabil, 13:894-900.

Kafatos A, Diacatou A, Voukiklaris G, et al. 1997. Heart disease risk-factor status and dietary changes in the Cretan population over the past $30 \mathrm{y}$ : the Seven Countries Study. Am J Clin Nutr, 65:1882-6.

Keys A, Menotti A, Karoven MI. 1986. The diet and the 15-year death rate in the Seven Countries Study. Am J Epidemiol, 124:903-15.

Knoops KTB, de Groot LCPGM, Kromhout D, et al. 2004. Mediterranean diet, lifestyle factors, and 10-year mortality in elderly European men and women, the HALE project. JAMA, 292:1433-9.

Kouris-Blazos A, Gnardellis C, Wahlqvist ML, et al. 1999. Are the advantages of the Mediterranean diet transferable to other populations? A cohort study in Melbourne, Australia. Br J Nutr, 82:57-61.

Lagiou P, Trichopoulos D, Sandin S, et al. 2006. Mediterranean dietary pattern and mortality among young women: a cohort study in Sweden. Br J Nutr, 96:384-92

Lasheras C, Fernandez S, Patterson AM. 2000. Mediterranean diet and age with respect to overall survival in institutionalized, non-smoking elderly people. Am J Clin Nutr, 71:987-92.

Lopez AD, Mathers CD, Ezzati M, et al. 2006. Global and regional burden of disease and risk factors, 2001: systematic analysis of population health data. Lancet, 367:1747-57.

Luchsinger JA, Mayeux R. 2004. Dietary factor's and Alzheimer's disease. Lancet (Neurology), 3:579-87.
Mantzoros CS, Williams CJ, Manson JE, et al. 2006. Adherence to the Mediterranean dietary pattern is positively associated with plasma adiponectin concentrations in diabetic women. Am J Clin Nutr, 84:328-35.

Martinez-Gonzalez MA, Fernandez-Jarne E, Serrano-Martinez M, et al. 2002. Mediterranean diet and reduction in the risk of a first acute myocardial infarction: an operational healthy dietary score. Eur $J$ Nutr, 41:153-60.

Martinez-Gonzalez MA, Sanchez-Villegas A. 2004. The emerging role of Mediterranean diets in cardiovascular epidemiology: monounsaturated fats, olive oil, red wine or the whole pattern? Eur J Epidemiol, 19:9-13.

Mendez MA, Popkin BM, Jakszyn P, et al. 2006. Adherence to a Mediterranean diet is associated with reduced 3-year incidence of obesity. J Nutr, 136:2934-8.

Michaelsen A, Lehmann N, Pithan C, et al. 2006. Mediterranean diet has no effect on markers of inflammation and metabolic risk factors in patients with coronary artery disease. Eur J Clin Nutr, 60:478-85.

Nestle M, ed. 1995. Mediterranean diets: science and policy implications. Am J Clin Nutr, 61(Suppl 6):1313-427.

Nkondjock A, Ghadirian P. 2007. Diet and BRCA-associated breast cancer risk. Breast Cancer Res Treat, 103:361-9.

Osler M, Schroll M. 1997. Diet and mortality in a cohort of elderly people in a north European Community. Int J Epidemiol, 26:155-9.

Panagiotakos DB, Arapi S, Pitsavos C, et al. 2006. The relationship between adherence to the Mediterranean diet and the severity and short-term prognosis of acute coronary syndromes (ACS): the Greek Study of ACS (the GREECS). Nutr, 22:722-30.

Panagiotakos DB, Chrysohoou C, Pitsavos C, et al. 2002. The association of Mediterranean diet with lower risk of acute coronary syndromes in hypertensive subjects. Int J Cardiol, 82:141-7.

Panagiotakos DB, Chrysohoou C, Pitsavos C, et al. 2006. Association between the prevalence of obesity and adherence to the Mediterranean diet: the ATTICA study. Nutr, 22:449-56.

Panagiotakos DB, Pitsavos C, Chrysohoou C, et al. 2004. Impact of lifestyle habits on the prevalence of the metabolic syndrome among Greek adults from the ATTICA study. Am Heart J, 147:106-12.

Panagiotakos DB, Pitsavos C, Chrysohoou C, et al. 2005. The epidemiology of type 2 diabetes mellitus in Greek adults: the ATTICA study. Diabet Med, 22:1581-8.

Panagiotakos DB, Pitsavos C, Matalas AL, et al. 2005. Geographical influences on the association between adherence to the Mediterranean diet and the prevalence of acute coronary syndromes, in Greece: the CARDIO 2000 STUDY. Int J Cardiol, 100:135-42.

Pitsavos C, Panagiotakos DB, Chrysohoou C, et al. 2003. The adoption of Mediterranean diet attenuates the development of acute coronary syndromes in people with the metabolic syndrome. Nutr J, 2:1.

Polychronopoulos E, Panagiotakos DB, Polystipioti A. 2005. Diet, lifestyle factors and hypercholesterolemia in elderly men and women from Cyprus. Lipids Health Dis, 4:17.

Rodriguez-Villar C, Perez-Heras A, Mercadē J, et al. 2004. Comparison of a high-carbohydrate and a high-monosaturated fat, olive oil-rich diet on the susceptibility of LDL to oxidative modifications in subjects with type 2 diabetes mellitus. Diabet Med, 21:142-9.

Salas-Salvado J, Garcia-Arellano A, Estruch R, et al. 2007. Components of the mediterranean-type food pattern and serum inflammatory markers among patients at high risk for cardiovascular disease. Eur J Clin Nutr, 1-9 (www.nature.com/ejcn).

Sanchez-Villegas A, Bes-Rastrollo M, Martinez-Gonzalez MA, et al. 2006. Adherence to a Mediterranean dietary pattern and weight gain in a follow-up study: the SUN cohort. Int J Obes (Lond), 30:350-8.

Scali J, Richard A, Gerber M. 2001. Diet profiles in a population sample from Mediterranean southern France. Public Health Nutr, 4:173-82.

Scarmeas N, Stern Y, Tang M-X, et al. 2006. Mediterranean diet and risk for Alzheimer's disease. Ann Neurol, 59:912-21.

Scarmeas N, Stern Y, Mayeux R, et al. 2006. Mediterranean diet, Alzheimer disease, and vascular mediation. Arch Neurol, 63:(doi:10.1001/archneur.63.12.noc60109). 
Schroder H, Marrugat J, Vila J, et al. 2004. Adherence to the traditional Mediterranean diet is inversely associated with body mass index and obesity in a Spanish population. J Nutr, 134:3355-61.

Serra Majem L, Helsing E, ed. 1993. Changing patterns of fat intake in Mediterranean countries. Eur J Clin Nutr, 47(Suppl 1):1-100.

Serra-Majem L, Roman B, Estruch R. 2006. Scientific evidence of interventions using the Mediterranean diet: a systematic review. Nutr Rev, 64:S27-47.

Serrano-Martinez M, Palacios M, Martinez-Losa E, et al. 2005. A Mediterranean dietary style influences TNF-alpha and VCAM-1 coronary blood levels in unstable angina patients. Eur J Nutr, 44:348-54.

Serrano-Martinez M, Martinez-Gonzalez MA. 2007. Effects of Mediterranean diets on plasma biomarkers of inflammation (letter). Eur J Clin Nutr, 28. doi:10.1038/sj.ejcn.1602599.

Singh N, Graves J, Taylor PD, et al. 2002. Effects of a "healthy" diet and of acute and long-term vitamin $\mathrm{C}$ on vascular function in healthy older subjects. Cardiovasc Res, 56:118-25.

Solfrizzi V, Panza F, Capurso A. 2003. The role of diet in cognitive decline. J Neural Transm, 110:95-110.

Solfrizzi V, Colacicco AM, D'Introno A, et al. 2006. Dietary intake of unsaturated fatty acids and age-related cognitive decline: a 8.5-year follow-up of the Italian Longitudinal Study on Aging. Neurobiol Aging, 27:1694-704.

Sondergaard E, Moller JE, Egstrup K. 2003. Effect of dietary intervention and lipid-lowering treatment on brachial vasoreactivity in patients with ischemic heart disease and hypercholesterolemia. Am Heart J, 145:E19.
Stathakos D, Pratsinis H, Zachos I, et al. 2005. Greek centenarians: assessment of functional health status and life-style characteristics. Exp Gerontol, 40:512-18.

Thanapoulou A, Karamanos B, Angelico F, et al. 2006. Epidemological evidence for the non-random clustering of the components of the Metabolic Syndrome Multicentre study of the Mediterranean Group for the study of Diabetes. Eur J Clin Nutr, 60:1376-83.

Trichopoulou A, Kouris-Blazos A, Wahlqvist ML, et al. 1995. Diet and overall survival in elderly people. $B M J, 311: 1457-60$.

Trichopoulou A, Costacou T, Bamia C, et al. 2003. Adherence to a Mediterranean diet and survival in a Greek Population. N Eng J Med, 348:2599-608.

Trichopoulou A, Naska A, Orfanos P, et al. 2005. Mediterranean diet in relation to body mass index and waist-to-hip ratio: the Greek European Prospective Investigation into Cancer and Nutrition Study. Am J Clin Nutr, 82:935-40.

Trichopoulou A, Orfanos P, Norat T, et al. 2005. Modified Mediterranean diet and survival: EPIC-elderly prospective cohort study. $B M J$, 330:991.

Waijers PMCM, Ocké MC, van Rossum CTM, et al. 2006. Dietary patterns and survival in older Dutch women. Am J Clin Nutr, 83:1170-6.

Willett WC, Sacks F, Trichopoulou A, et al. 1995. Mediterranean diet pyramid: a cultural model for healthy eating. Am J Clin Nutr, 61(Suppl 6):1402-6.

WHO. 2001. Mental health: new understanding, new hope: world health report 2001. Geneva: World Health Organization. 
